\title{
Genealogías literarias: el realismo de Dublineses de James Joyce y su influencia en la generación de narradores peruanos de los 50
}

\section{Literary genealogies: Realism in James Joyce's Dubliners and his influen- ce on the generation of Peruvian storytellers of the $1950 \mathrm{~s}$}

Jorge Valenzuela Garcés ${ }^{1}$

Universidad Nacional Mayor de San Marcos. Lima, Perú

jorgevalenzuela4@hotmail.com

ORCID: 0000-001-8886-699X

Citar como: Valenzuela Garcés, J. (2019). Genealogías literarias: el realismo de Dublineses de James Joyce y su influencia en la generación de narradores peruanos de los 50. Desde el Sur, 11(2), pp. 217-226.

\section{RESUMEN}

Este artículo busca establecer la relación entre el realismo joyceano, plasmado en su libro Dublineses, publicado en 1914, y la producción narrativa de los escritores neorrealistas peruanos de los años 50 . El análisis emplea como marco teórico la poética del realismo naturalista y se centra en la descripción narratológica del tiempo y del narrador en algunos de los cuentos de Joyce y de narradores peruanos como Ribeyro.

\section{PALABRAS CLAVE}

James Joyce, Dublineses, realismo, cuento peruano, generación del 50

\section{ABSTRACT}

This article seeks to establish the relationship between Joycean realism, embodied in his book of short stories Dubliners, published in 1914, and the narrative output of the Peruvian neorealist writers of the 1950s. The theoretical framework employed for this analysis is the poetics of naturalistic realism, with a focus on the narratological

1 Profesor principal del Departamento de Literatura de la Facultad de Letras y Ciencias Humanas de la Universidad Nacional Mayor de San Marcos. Es doctor en Literatura Hispanoamericana por la Universidad Complutense de Madrid. 
description of time and the narrator in stories by Joyce and Peruvian writers such as Ribeyro.

\section{KEYWORDS}

James Joyce, Dubliners, realism, Peruvian storytelling, 1950s generation

\section{Introducción}

Antes de convertirse en el máximo representante de la vanguardia narrativa de Occidente, James Joyce cumplió con asumir y relajar, a través del relato corto, las lecciones del realismo naturalista. Su poética del cuento, visible en Dublineses (1914), le demostró al lector en español que cualquier aspecto de la vida podía convertirse en un cuento, como en Chejov, y que la vida en las ciudades empezaba a convertirse en el centro de la atención de los escritores europeos, como luego sucedería, en los años 50, con los escritores latinoamericanos.

Las primeras traducciones del libro al español ${ }^{2}$ datan de 1942, cuando el libro se publica en Barcelona con el título de Gente de Dublín por la Editorial Tartesos. En nuestro continente, la primera traducción es de 1945 y fue publicada en Santiago de Chile por la editorial Ercilla, con traducción de Luis Alberto Sánchez.

Tres de los primeros cuentos que escribió para Dublineses fueron encargados por la revista de granjeros The Irish Homestead, pero fueron rechazados por el editor, George Russell, por no adecuarse a la naturaleza de los lectores a la que iba dirigida la publicación. Ese rechazo, sin embargo, no hizo sino estimular a Joyce en la tarea de continuar con la escritura de más relatos, hecho que tuvo lugar en Trieste y Roma, después de dejar Dublín en 1904.

La travesía que supuso la publicación del libro estuvo marcada por la censura y la indiferencia. El libro fue presentado a 15 editores unas 18 veces. Joyce no estaba dispuesto a realizar cambios que supusieran una traición al propio espíritu del libro. Así, después de haberlo presentado al editor y novelista Grant Richards en 1906 y de verse inmiscuido en demandas de todo tipo presentadas por impresores y editores, volvió nuevamente a Richards, quien, finalmente, en 1914, lo editó. 


\section{El realismo narrativo de Dublineses}

Uno de los principales debates en torno a Dublineses es el tipo de filiación que establece con la tradición del realismo narrativo. El libro, se preguntan la crítica y los lectores, ¿está más cerca del realismo de Flaubert o del de Zola? ¿Más cerca de ese primer realismo aún influenciado por ciertos rezagos románticos o sigue la estela del realismo naturalista, beligerante y cientificista?

De un lado, según su biografía y testimonios, el propio Joyce se preciaba de haber leído todo Flaubert y de haber aprovechado sus lecciones. De otro, tenemos en Dublineses elementos que nos permiten calibrar el influjo del naturalismo zoliano de la época, con sus pretensiones documentales, la preocupación moral y la búsqueda de la verdad. Mario Vargas Llosa sostiene que: "El "naturalismo" de Joyce, a diferencia del de Zola, no es social, no está guiado por otra intención que la estética» (2002, p. 63). Veamos.

En principio, Dublineses es un libro que deja como herencia, a los narradores hispanoamericanos de la segunda mitad del siglo XX, las creencias, modos y presupuestos del realismo decimonónico ${ }^{3}$. Allí está la preocupación por las interacciones del individuo con la sociedad, el marco opresivo de la ciudad, el aprendizaje de la vida, el gran peso del prestigio social, los prejuicios de la clase media, y, sobre todo, el intento de hacer pasar la ficción como la realidad. Pero lo más importante es el «efecto de reconocimiento» que lleva al lector a (re)encontrar lo «real» en el «texto» (Perus, 2012, p. 23). En efecto, en Dublineses de Joyce, los elementos que hacen que un cuento cumpla con el llamado "pacto realista» son diversos, pero quizá el más importante tenga que ver con el reconocimiento que pueda hacer el lector, en el texto, de un entorno que le sea familiar, afín, y dentro del cual pueda proyectar sus propias expectativas y sentimientos sin experimentar una crisis de percepción o de apropiación del mundo.

Un segundo elemento realista es el que vincula al lector con personajes y destinos ligados a ese medio a partir de una dinámica en la que la lógica de los acontecimientos no sea subvertida por algún elemento extraño; esto implica que los hechos narrados deben estar articulados a partir de una fuerte relación de causa-efecto de la cual se sigue, lógicamente, el devenir de los personajes y sus acciones. Este último elemento es sumamente importante, porque la interpretación que haga el narrador de esa relación lo legitimará como un instrumento confiable en la decodificación

3 Para la definición general de realismo del siglo XIX empleamos el libro de François Perus sobre Juan Rulfo en que atiende al Ilamado «pacto realista» y al modo en que los escritores hispanoamericanos del siglo XX, ponen en cuestión sus principales premisas. Ver bibliografía. 
de las relaciones individuales y sociales comprometidas en el universo representado. Sumemos a todo esto, el empleo, por parte del narrador, de un lenguaje cuya transparencia trasmita esa confianza en la posibilidad de representar lo «real» en el texto.

Como parte de este conjunto de presupuestos, mencionemos, además, una importante estrategia discursiva: la práctica del llamado objetivismo, resultado del manejo de la perspectiva narrativa. Se trata, en este último aspecto, de la manipulación de la información diegética que restringe el campo de la representación a lo puramente externo. Así, estamos ante el propósito de conseguir un efecto lenguaje que busca eliminar cualquier evidencia de la intervención del narrador manteniendo a raya una posible contaminación subjetiva que pudiera supeditar lo narrado a un determinado punto de vista. A esto se refiere François Perus cuando menciona que en el realismo del XIX el sujeto de la enunciación se postula como un "sujeto supuestamente neutro que se asemeja al de la ciencia positiva», cuya «labor de desentrañamiento, interpretación y transposición de lo «real» al plano de la ficción descansa en buena medida en las diversas concepciones acerca de lo «natural», lo «individual» y lo «social» vigentes en las sociedades decimonónicas o de principios del siglo XX» (2012, p. 23).

Los cuentos de Dublineses nos permiten observar estos elementos que, al decir del propio Joyce, fueron empleados por él con un propósito claro: «traicionar el alma de esa hemiplejia o parálisis a la que muchos consideran una ciudad». La propuesta es, de este modo, programática. Los cuentos del libro, sin embargo, se esfuerzan en demostrar que la única forma de escapar de esa parálisis es recreándola, ficcionalizándola, no retratándola, lo cual hubiese implicado seguir en el pantano del realismo decimonónico. Si esto significa dar un paso en la conciencia crítica de la postura realista, pues Joyce lo dio. Me explico. Los realistas del XIX apostaban por la fidelidad al referente, eso que se ha llamado «falacia genética del realismo» o «realismo ingenuo», posición que parte del supuesto de que existe una correspondencia entre una realidad que se percibe como unidimensional, previa al texto, y el texto, que es considerado como una proyección de la vida sin mediaciones. De allí la fe en la posibilidad de representar la verdad o de alcanzarla a través de la literatura. De allí, también, la idea de que los escritores realistas, por estas creencias estéticas, fueran inevitablemente tomados como artistas «sinceros» $\mathrm{u}$ «honestos».

Con Dublineses, y esa es su lección, se parte de la idea de que la realidad no es algo que esté previamente establecido o que exista antes del texto, como pensaban los realistas ingenuos. Por ello, si bien hay rasgos naturalistas en casi todos los cuentos, estos no lo son en el sentido 
estricto y experimental, al modo zoliano, y no constituyen una limitación en el propósito de generar un universo autónomo y plenamente estético. Hernán Lara ha determinado que «entre la escritura de Dublineses y Retrato del artista adolescente Joyce se transformó de un escritor meramente naturalista en uno más intimista y simbólico gracias a que su prosa ganó agilidad y aliento lírico mediante el uso del estilo indirecto libre, así como a su gran descubrimiento del concepto de «epifanía» (2014, p. 15). Concepto que le sirve para concentrar en un solo momento una revelación, el levantamiento del velo, el conocimiento de «los misterios que rodeaban la vida de sus pobladores, los secretos que ocultaban cotidianamente» (2014, p. 15).

Para comenzar, la conciencia narrativa que percibe los fenómenos representados, si bien observa y describe el entorno social, no lo hace desde el prejuicio cientificista o positivo. Todo lo contario, la conciencia que percibe se proyecta sobre el individuo y se limita a dar cuenta de sus contradicciones desde un tipo de focalización que evidencia una interioridad conflictiva, confusa y hasta contradictoria, y, por ello, mismo, independiente, libre del influjo temperamentalista y de la herencia genética del naturalismo. El narrador joyceano presenta a sus personajes en un proceso de desintegración, pérdida y desorientación en el cual no ejerce ninguna manipulación. Citemos un fragmento del cuento «Eveline»: «Ella había decidido dejar la casa, irse lejos. ¿Era esta una decisión inteligente? Trató de sopesar las partes del problema. En su casa por lo menos tenía casa y comida; estaban aquellos que la conocían de toda la vida. Claro que tenía que trabajar duro, en la casa y en la calle. ¿Qué dirían en la tienda cuando supieran que se había fugado con el novio?». Joyce observa al sujeto libre de las ataduras del naturalismo y lo despliega en el ejercicio de su libre albedrío. Sujetos en crisis, los personajes del libro se debaten entre el disfrute de su libertad y la renuncia a ella; entre la afirmación del respeto a uno mismo y la pérdida de todo reparo.

Ahora bien, debe reconocerse que, en algunos cuentos, la lógica del relato se articula a la causalidad y a cierto determinismo. Es lo que podríamos denominar «trama fuerte». Es el caso de «Counterparts», traducido como «Duplicados» o «Copias simples», en el que, hacia el final del relato, el maltrato contra un niño, el hijo de Farrington, se convierte en el efecto de la permanente humillación recibida por este en el trabajo y en el bar. Casi convertido en un cuento de tesis, la historia no puede dejar de postular un hecho: los otros son decisivos en la conducta de los seres humanos cuya consecuencia inevitable es perpetuar, en la descendencia, la frustración y el odio hacia los demás. 
A caballo entre el legado más bien disminuido del realismo naturalista, los cuentos, como ciclo narrativo, construyen un universo en el que si bien la ciudad de Dublín es central en la configuración del mundo representado, no lo es tanto en el perfil de los personajes. Insistimos. Los héroes son en su mayoría decadentes, experimentan el desasosiego y la necesidad de escapar del mundo que los rodea (como en el caso del personaje del cuento «Eveline»), pero, o no tienen el valor para hacerlo o se ven dominados por una fuerza superior que los paraliza. En muchos de los relatos de Dublineses, los protagonistas luchan consigo mismos en el propósito de resolver sus conflictos internos frente a los cuales, invariablemente, fracasan. Por ello han dejado de ser los héroes clásicos que se enfrentan a la sociedad. Ahora, ellos mismos, son sus propios enemigos.

Sumidos en la confusión de sus sentimientos o en la falta de perspectiva para verse a sí mismos, personajes como Mr. James Duffy en «A painful case», traducido como «Lamentable caso» o «Un triste caso», incurren en el egoísmo más cruel, la desafección y en la falta de tino para relacionarse con el sexo opuesto. Construido a partir de una descripción que nos permite conocerlo gracias a la habitación que ocupa, los libros que lee y los rasgos de su rostro, Duffy es el emblema del ermitaño que no tiene «compañeros, ni amigos, ni iglesia ni credo». Su vida es percibida como un relato «carente de aventuras» y le es atribuida la siguiente creencia: «todo lazo es una atadura dolorosa». Seguidor de Nietzsche por los libros que reposan en sus estantes, Duffy no cree en la posibilidad de establecer una relación igualitaria con la mujer a la que ve como un ser incapaz de mantener una amistad. Así, Mrs. Emily Sinico es un ser disminuido de quien se aparta, guiado por sus creencias y prejuicios. Crítica feroz contra la prédica nietzschiana y sus excesos, accedemos, sin embargo, hacia el final del relato, a un esperanzador estado de conciencia que le permite a Duffy reconocerse, patéticamente, en la absoluta soledad.

Hechos los balances, a poco más de los cien años de la publicación de este libro, Dublineses puede considerarse como esa guía que nos permitió, a lo largo del siglo XX, explorar en la frustrada modernidad del segmento de la clase media internacional, y en aquellos procedimientos técnicos cuya función es otorgarle belleza y autonomía estética a un texto literario. Lejos de las ataduras de ese narrador autoritario y entrometido del XIX, el libro rezuma un estilo sobrio que, como decía Pound, no incurre en la sátira descalificante ni en el humor inútil.

Libro que configura al fracaso personal y social en sus diversas modalidades, Dublineses posee la cualidad de no renunciar a las posibilidades del realismo en un momento en el que las vanguardias pugnaban por imponer su discurso. Así, persuadido de la necesidad de vincular el horizonte 
moral con el estético, el libro supera con creces las amenazas del didactismo naturalista y las tesis cientificistas que buscaban convertir a los personajes de ficción en pretextos para la experimentación social.

\section{El realismo de Joyce y la narrativa peruana de los $\mathbf{5 0}$}

\section{El manejo del tiempo}

En la narrativa de los años 50 el tratamiento de la dimensión temporal se supedita, en gran medida, a la exploración de la conciencia de los personajes. Es la primera influencia del magisterio joyceano, a partir de Dublineses, en escritores peruanos como Carlos Eduardo Zavaleta, quien, desde sus primeros cuentos — pensemos en «Una figurilla»—, se limita a dar cuenta, a través de su narrador, de una interioridad agraviada.

El tiempo se emplea para advertir la parálisis del personaje gracias a las demandas de su propio elenco de sentimientos enmarcados en un tiempo interior fracturado, decisivo en su vida. La parálisis referida por el propio Joyce como efecto de la imposibilidad de los personajes de asimilarse al proyecto de modernización propuesta por la dinámica social, se materializa en la suspensión del paso del tiempo exterior y en la concentración de una temporalidad que se ancla en el pasado, en el recuerdo o rememoración. El peso de este tiempo y los compromisos sentimentales establecidos con otros seres humanos serán decisivos en la manifestación de esa parálisis. Sin posibilidades de abrirse a la regeneración de sus propias vidas, el manejo del tiempo sirve para hacer patente, a partir de soliloquios o monólogos, esas largas pausas temporales que detienen el fluir del relato. El ritmo narrativo con pausas, retrospecciones, sumarios está allí para evidenciar la naturaleza de una interioridad alienada, humillada o violentada, incapaz de superar los tradicionales modos de inserción e intercambio social que se presentan como naturales.

\section{El narrador}

Si bien la perspectiva crítica del narrador joyceano se inscribe dentro del naturalismo narrativo y del programa de regeneración social que imponía, para Vargas Llosa esta no es relevante. Citemos: «Aunque la visión de la sociedad que los cuentos de Dublineses ofrecen es severísima - a veces sarcástica, a veces irónica, a veces abiertamente feroz-, este es un aspecto secundario del libro. Sobre lo documental y crítico prevalece lo artístico» (2002, p. 61).

En efecto, siguiendo las primeras críticas de Pound al libro de Joyce, Vargas Llosa destaca, en el libro, las habilidades de un narrador que apuesta por la objetividad. ¿Cómo funciona este narrador en el libro? ¿Cómo se manifiesta esa objetividad? «Aparece primero organizando el 
mundo narrativo, dando al estilo su coherencia y movimiento específico, estableciendo un sistema de acercamiento y distancia entre el lector y lo narrado» (2002, p. 61). Para Vargas Llosa es tanta la independencia de lo narrado con respecto al narrador que llega a sostener que «mientras estamos inmersos en su magia (la del libro), esa sordidez no puede ser más beIla ni sus gentes —aun las más ruines y chatas - más fascinantes» (2002, p. 63). En efecto, para el novelista peruano esta independencia logra generar un prodigio tratándose de la prosa naturalista: despoja al texto de una intención moralizante o de censura. Las circunstancias y los actos que comprometen a los personajes merecen de nosotros, como lectores, un rechazo y hasta nuestra condena, pero ese termina siendo nuestro trabajo.

Es cierto, el narrador logra generar en Dublineses el efecto de un mundo que se genera solo y en el que los personajes se encuentran expuestos a sus propias decisiones y pensamientos, sin la necesidad de ser habilitados por el comentario de un narrador impertinente. De allí la filiación flaubertiana en la que Vargas Llosa prefiere situar al escritor irlandés.

Gracias a este manejo del narrador, Joyce se convierte en una influencia inevitable para la narrativa peruana de los 50. Mostremos algunos ejemplos. Una de las primeras constataciones que puede realizarse cuando uno observa al narrador en Ribeyro es que este está elaborado y planeado para evitar que se filtren, a través de él, juicios de valor u opiniones. El narrador, además, nos proporciona información concisa, puntual, económica y alejada de esa emotividad cuyo objetivo es manipular al lector a través de sentimientos positivos. Es más, su narrador, de raíz escéptica, logra, a partir de una distancia premeditada, que los personajes de sus cuentos se muestren en toda su soledad y orfandad. El narrador de Ribeyro prefiere relatar, asimismo, trayectorias vitales signadas por el fracaso, la muerte o la inminente disolución personal como Joyce. A esto se refiere José Miguel Oviedo cuando habla del valor de la obra cuentística del autor de «Los gaIlinazos sin plumas». Hay en Ribeyro «una predisposición para la observación precisa y reveladora del contexto que la acompaña; cierto gusto por los detalles triviales apuntados en simples pinceladas, pero que se van acumulando como símbolos y claves de un destino particular; un interés por vidas resignadas a su falta de grandeza, cuya peripecia puede ser contada en pocas palabras, pero desde un ángulo que connota su secreto horror, su íntima y desgarradora tristeza. Humildes personajes, pequeños actos, grandes ilusiones: ese juego de elementos, típico en Ribeyro, conduce casi invariablemente a la derrota y a la convicción de que no importa cuál sea nuestra ambición —el amor, la aventura, el poder, el dinero, la figuración social- siempre estamos solos e indefensos» (1983, p. 198). 
Como en el caso de Joyce, el narrador de Ribeyro también se ejercita en la focalización externa para objetivizar el mundo representado y, de este modo, controlar cualquier exabrupto, cualquier extralimitación que pudiera generarse desde el ámbito de sus pareceres.

La segunda característica del narrador de Ribeyro, como en Joyce, es que estamos ante uno cuyas descripciones se producen frente al estímulo de relaciones interpersonales afectadas por el deterioro o el miedo. Sumemos a ello que el narrador repara en relaciones entre sujetos en condiciones marcadas por la subordinación o sumisión. Por ello, el narrador centra su atención en la naturaleza de las relaciones de poder y en los efectos que estas tienen sobre los personajes.

El espacio elegido por este narrador es el de la ciudad. Este espacio, en muchos casos, está marcado por la decadencia. Por ello quien narra elige espacios cerrados, bares, casas o quintas a las que no ha llegado la modernidad como si en esos espacios se pudiese diagnosticar mejor la imposibilidad de cambiar.

\section{Conclusiones}

La influencia de Joyce y de su libro Dublineses se manifiesta en el empleo de la focalización externa, el estilo indirecto libre y en la inclusión de un tono lírico que apunta a otorgarle al relato una dimensión simbólica. Este empleo libera al relato de la intrusión del narrador y provee al lector de la posibilidad de una interpretación generada a partir de su propio trabajo decodificador.

El narrador desarrolla una estrategia que implica una absoluta libertad en el desempeño de sus personajes que proyectan un recorrido narrativo que los orienta a la disolución y al fracaso, temas presentes en los cuentos de los principales narradores peruanos de la generación del 50. La presencia de un narrador escéptico y hasta irónico en los cuentos de autores como Ribeyro es consecuencia de ese manejo joyceano.

Joyce se inscribe dentro del realismo, pero se aparta de las condiciones que impone el naturalismo narrativo al despojar a sus textos de la explícita crítica social y de la intervención de un narrador editorialista. Su mirada lírica y ensimismada, producto de su poética de la «epifanía», es el antecedente de la narrativa neorrealista de la generación del 50. 


\section{Contribuciones}

Jorge Valenzuela Garcés ha participado en la concepción del artículo, la recolección de datos, su redacción y aprobación de la versión final.

\section{Fuente de financiamiento}

Autofinanciado.

\section{Conflicto de interés}

El autor declara no tener conflictos de interés.

\section{REFERENCIAS BIBLIOGRÁFICAS}

García Tortosa, F. (1994). Las traducciones de Joyce al español. En F. García Tortosa y A. Raúl de Toro Santos (Eds.), Joyce en España. IV Encuentros de la Asociación Española James Joyce. A Coruña: Universidade. Servizo de publicacións, vol. l, pp. 19-29. Recuperado de https://idus.us.es/xmlui/bitstream/handle/11441/18004/file_1.pdf?sequence=1\&isAllowed=y

Joyce, J. (2015) Dublineses. Buenos Aires: Akal.

Lara Zavala, H. (2014). El laboratorio del Dublín. Revista de la Universidad de México, 129, pp. 14-18. Recuperado de http://www.revistadelauniversidad.unam.mx/ojs_rum/index.php/rum/article/view/16398/18176

Oviedo, J. M. (1983). La lección de Ribeyro. Eco. Revista de Cultura de Occidente, tomo XLIV, 2(266), pp. 197-201.

Perus, F. (2012). Juan Rulfo, el arte de narrar. Ciudad de México: Universidad Autónoma de México.

Vargas Llosa, M. (2002). El Dublín de Joyce. En La verdad de las mentiras (pp. 57-66). Madrid: Alfaguara. 